\title{
Lactate as an early predictor of psychomotor development in neonates with asphyxia receiving therapeutic hypothermia
}

\author{
Renata Polackova ${ }^{\mathrm{a}, \mathrm{b}}$, Dana Salounovac, Lumir Kantor ${ }^{\mathrm{d}}$
}

\begin{abstract}
Aims. This prospective study aimed to evaluate the relationship between persistently elevated lactate values in the arterial blood of newborns with grade II and III hypoxic ischemic encephalopathy (treated with therapeutic hypothermia) and psychomotor development at 24 months.

Methods. 51 neonates of gestational age from 36 to 41 weeks receiving therapeutic hypothermia for moderate to severe hypoxic ischaemic encephalopathy had arterial blood lactate levels regularly analysed. At 24 months the infants' psychomotor development was evaluated and they were divided into two groups - those where the outcome was favourable (i.e. normal psychomotor development) and adverse (severe motor or sensory impairment or death). The lactate dynamics over time were retrospectively evaluated from the data collected, with the normal upper limit set at $4 \mathrm{mmol} / \mathrm{L}$.

Results. Of the 51 affected neonates, 7 died over the course of the study. 34 of the remaining 44 infants demonstrated normal psychomotor findings at 2 years old, with adverse findings in 10 cases. Although both groups experienced significant reductions in lactate over time, there were statistically significant differences between them regarding currently measured lactate levels.

Conclusion. Absolute lactate values and their development over time can be a used as an auxiliary factor in making early estimates of the long-term outcome for newborns with neonatal asphyxia being treated with therapeutic hypothermia.
\end{abstract}

Key words: lactate, newborn, asphyxia, encephalopathy, outcome

Received: July 30, 2017; Accepted: November 21, 2017; Available online: December 4, 2017 https://doi.org/10.5507/bp.2017.052

${ }^{a}$ Department of Paediatrics and Neonatology, Faculty of Medicine, University of Ostrava, Ostrava, Czech Republic ${ }^{b}$ Department of Paediatrics, Faculty of Medicine and Dentistry, Palacky University Olomouc, Czech Republic 'Department of Mathematical Methods in Economy, VSB - Technical University of Ostrava, Ostrava, Czech Republic ${ }^{d}$ Department of Neonatology, University Hospital Olomouc, and Faculty of Medicine and Dentistry, Palacky University Olomouc, Czech Republic

Corresponding author: Renata Polackova,e-mail: rekol@seznam.cz

\section{INTRODUCTION}

Hypoxic ischaemic encephalopathy (HIE) is an insult to the central nervous system (CNS) of a full-term neonate due to perinatal asphyxia (PA). According to the World Health Organisation, PA is the 5th highest cause of death in children under 5 years old (8\%). In developed nations, HIE occurs in 1 to 2 per 1000 newborns and 2 to 9 per 1000 live births worldwide ${ }^{1}$.

Treatment of neonatal asphyxia in the past was limited to symptomatic and supportive treatment until, in 2010, 2 meta-analyses of multicentric studies were published which conclusively confirmed the positive effect of therapeutic hypothermia (TH) (ref., ${ }^{2,3}$ ). The key prognostic factor in determining the outcome of HIE treatment is the current clinical status of the newborn according to Sarnat \& Sarnat staging, which is used to differentiate between mild, moderately severe and severe forms of HIE (ref. ${ }^{4}$ ). In mild HIE, a favourable prognosis does not require TH. In moderately severe cases, the rate of adverse outcomes falls from $48 \%$ in untreated patients to $32 \%$ of those who undergo TH. In severe cases, the effect of TH is lower, with adverse outcomes in $72 \%$ of TH-treated pa- tients, compared to $85 \%$ in untreated patients, who die or have serious neurological consequences ${ }^{5}$. The prognosis is usually unfavourable in such cases, even if abnormal neurological findings are detected at the time of hospitalization $^{6}$.

It is very difficult to provide a prognosis for children with HIE as efforts to estimate outcomes can be frustrated for a number of reasons, described as follows: 1. TH is subjectively regarded as unpleasant, even painful. Hence, patients are given analgesics during the treatment. 2. Convulsions often occur in children with moderately severe to severe HIE, when it is necessary to give them antiepileptics. 3. The majority of severely asphyxiated neonates require respiratory support. These situations confound the physiological and pathological manifestations. In this way, they preclude the monitoring of prognostic markers - positive or negative - such as state of consciousness, muscle tone, spontaneous physical activity, convulsions, vegetative reaction to external stimuli, etc. Several factors are currently being investigated for making HIE prognosis: clinical examination, CNS imaging and amplitude EEG (aEEG) (ref. $\left.{ }^{6-8}\right)$. 1. Clinical examination of the newborn (according to Sarnat 
\& Sarnat staging) and diagnosing mild encephalopathy are associated with very favourable prognoses, whereas severe encephalopathy is associated with adverse prognoses. 2. Brain magnetic resonance (MRI) in the first week of life can provide a prognosis based on the severity of changes in the thalamus, basal ganglia, white matter and cerebral cortex. 3. Normalization of aEEG records within $24 \mathrm{~h}$ of hypoxic insult is a positive prognostic marker ${ }^{9,10}$. Earlier studies, conducted before the advent of TH, using proton magnetic resonance spectroscopy $\left({ }^{1} \mathrm{H} \mathrm{MRS}\right)$ to examine the brain, showed, that persistently elevated lactate levels in cerebral tissue soon after birth asphyxia are associated with adverse neurological development at 12 months old ${ }^{11,12}$. However, this investigative method is not routinely performed. Recently, work has been done to measure localized brain saturation in asphyxiated newborns during TH. Near-infrared spectroscopy (NIRS) appears to be a valuable non-invasive method, which, taken together with the current aEEG, fulfills a valuable role as an early predictor of the long-term outcome ${ }^{13}$. All these predictors are key to how well we are informed regarding current treatment effectiveness, which in turn enables us to provide the most timely and objective information possible to parents during this extremely stressful situation. This aside, in the end it is still a matter of conjecture. Hence, additional diagnostic methods and biochemical markers are being pursued which will improve the accuracy of our predictions. The results published here show that monitoring arterial blood lactate dynamics may be a useful variable in refining the long-term prognosis of asphyxiated neonates undergoing $\mathrm{TH}$.

\section{MATERIALS AND METHODS}

This prospective study comprises 51 neonates diagnosed with moderate and severe HIE (otherwise known as HIE grade II and III). The study group includes 35 newborns with HIE grade II and 16 with HIE grade III. All patients were treated in the neonatal department at the perinatal center of the University Hospital Ostrava. $33.3 \%$ of the cohort were born at this hospital and $66.6 \%$

Table 1. Initial parameters of patients selected for the study.

\begin{tabular}{|c|c|c|c|}
\hline Parameters & $\begin{array}{l}\text { Favourable outcome } \\
(\mathrm{n}=34)\end{array}$ & $\begin{array}{l}\text { Adverse outcome } \\
(n=17)\end{array}$ & $P$ \\
\hline $\begin{array}{l}\text { Birthplace } \\
\text { inborn }(\mathrm{n}(\%)) \\
\text { outborn }(\mathrm{n}(\%))\end{array}$ & $\begin{array}{l}14(41.2) \\
20(58.8)\end{array}$ & $\begin{array}{c}3(17.6) \\
14(82.4)\end{array}$ & $\begin{array}{c}0.093 \\
\text { Chi-squared test }\end{array}$ \\
\hline $\begin{array}{l}\text { Delivery method } \\
\text { vaginal }(\mathrm{n}(\%)) \\
\text { Caesarean section }(\mathrm{n}(\%))\end{array}$ & $\begin{array}{l}20(58.8) \\
14(41.2)\end{array}$ & $\begin{array}{c}7(41.2) \\
10(58.8)\end{array}$ & $\begin{array}{c}0.234 \\
\text { Chi-squared test }\end{array}$ \\
\hline $\begin{array}{l}\text { Gestational age } \\
\text { average } \pm \text { SD (median) }\end{array}$ & $38.24 \pm 1.89$ & $38.71 \pm 1.83(39)$ & $\begin{array}{c}0.474 \\
\text { median test }\end{array}$ \\
\hline $\begin{array}{l}\text { Birth weight }(\mathrm{g}) \\
\text { average } \pm \text { SD (median) }\end{array}$ & $3044 \pm 508(3080)$ & $3270 \pm 608(3450)$ & $\begin{array}{l}0.060 \\
\text { median test }\end{array}$ \\
\hline $\begin{array}{l}\text { Sex } \\
\text { male }(\mathrm{n}(\%)) \\
\text { female }(\mathrm{n}(\%))\end{array}$ & $\begin{array}{l}21(61.8) \\
13(38.2)\end{array}$ & $\begin{array}{l}11(64.7) \\
6(35.3)\end{array}$ & $\begin{array}{c}0.838 \\
\text { Chi-squared test }\end{array}$ \\
\hline $\begin{array}{l}\text { Umbilical } \mathrm{pH} \\
\text { average } \pm \mathrm{SD} \text { (median) }\end{array}$ & $6.98 \pm 0.18(6.99)$ & $6.86 \pm 0.16(6.84)$ & $\begin{array}{c}0.136 \\
t-\text { test }\end{array}$ \\
\hline $\begin{array}{l}\text { Umbilical BE } \\
\text { average } \pm \text { SD (median) }\end{array}$ & $-16.31 \pm 6.10(-16.15)$ & $-19.28 \pm 6.66(-21.90)$ & $\begin{array}{c}0.337 \\
t-\text { test }\end{array}$ \\
\hline Convulsions (n (\%)) & $30(88.2)$ & $16(94.1)$ & $\begin{array}{c}0.654 \\
\text { Fisher's test }\end{array}$ \\
\hline Hypotension > 24 h (n (\%)) & $29(85.3)$ & $16(94.1)$ & $\begin{array}{l}0.650 \\
\text { Fisher's test }\end{array}$ \\
\hline $\begin{array}{l}\text { Initial } \mathrm{pH} \text { on admission } \\
\text { average } \pm \mathrm{SD} \text { (median) }\end{array}$ & $7.20 \pm 0.10(7.21)$ & $7.12 \pm 0.25(7.22)$ & $\begin{array}{c}0.276 \\
\text { median test }\end{array}$ \\
\hline $\begin{array}{l}\text { Initial } \mathrm{BE} \text { on admission } \\
\text { average } \pm \mathrm{SD} \text { (median) }\end{array}$ & $-13.16 \pm 5.34(-12.30)$ & $-18.21 \pm 8.75(-15.60)$ & $\begin{array}{c}<0.0005 \\
t-\text { test }\end{array}$ \\
\hline $\begin{array}{l}\text { Lactate values at time } \\
\text { of admission }(\mathrm{mmol} / \mathrm{L}) \\
\text { average } \pm \mathrm{SD}(\text { median })\end{array}$ & $9.10 \pm 5.75(8.25)$ & $15.75 \pm 5.93(15.50)$ & $\begin{array}{c}0.002 \\
\text { median test }\end{array}$ \\
\hline
\end{tabular}


Table 2. Change in lactate levels $(\mathrm{mmol} / \mathrm{L})$ in both groups of patients.

\begin{tabular}{lccc}
\hline Lactate - age of newborn & Favourable outcome & Adverse outcome & $P$ \\
\hline Lactate at $3 \mathrm{~h}$ & $7.78 \pm 6.28(4.40)$ & $14.74 \pm 5.87(14.20)$ & 0.001 \\
Lactate at $6 \mathrm{~h}$ & $6.19 \pm 5.36(3.70)$ & $12.38 \pm 6.20(13.70)$ & 0.002 \\
Lactate at $12 \mathrm{~h}$ & $4.55 \pm 3.97(2.45)$ & $10.95 \pm 7.51(1.55)$ & 0.012 \\
Lactate at $24 \mathrm{~h}$ & $3.33 \pm 2.64(2.40)$ & $9.88 \pm 8.22(6.15)$ & 0.002 \\
Lactate at $36 \mathrm{~h}$ & $2.68 \pm 2.05(1.95)$ & $9.21 \pm 7.91(5.70)$ & 0.002 \\
\hline
\end{tabular}

were transferred from the catchment area. The neonates were born between weeks 36 to 41 of gestation, with birth weights ranging from 1810 to 3995 grams. $52.9 \%$ were born vaginally; $47.1 \%$ by caesarean section. All fulfilled the criteria for undergoing $\mathrm{TH}$ and underwent the therapy for 72 $\mathrm{h}\left(\right.$ ref. $\left.^{14}\right)$. For the purposes of the study, the patient's internal environment (including lactate value) was monitored upon admission and during treatment in the $3^{\text {rd }}, 6^{\text {th }}, 12^{\text {th }}$, $24^{\text {th }}$ and $36^{\text {th }} \mathrm{h}( \pm 30 \mathrm{~min})$ of the newborn's life. All blood samples were taken from arteries in the umbilicus or limbs, and immediately examined with an identical bed-side analyzer. Following the conclusion of treatment, the patient was monitored until 2 years old, at which time the child's psychomotor development was definitively established by a neurologist and neonatologist using the Gross Motor Function Classification System (GMFCS), and subsequently assigned to one of two groups according to whether the judgement obtained was favourable or adverse ${ }^{15}$. The adverse outcome group were patients who died, or survived with severe disability (GMFCS level II-V; severe cognitive impairment, deafness, blindness). Table 1 details the initial parameters of both groups at the time of inclusion in the study; the characteristics described do not differ for the majority of parameters. The base excess values (BE) and lactate upon admission are statistically significant in that they support the fact that the study indeed comprises only patients with moderately severe and severe asphyxia. The lactate dynamics of the groups were analysed at the time of treatment, with the normal upper limit set at $4 \mathrm{mmol} / \mathrm{L}$. In evaluating the sample cohort, chi-squared-, median-, $t$-, and Fisher's exact test were used. The median test was applied in comparisons of lactate dynamics in the two groups.

\section{RESULTS}

The 51 selected children with grade II and III HIE were placed into 2 groups based on the final evaluation of their psychomotor development at 2 years old. The outcome was judged favourable in 34 of these cases and adverse in 17 ( 10 survived with severe disabilities; 7 died as a result of HIE). The neonates with HIE grade II demonstrated favourable outcome in 31 cases $(88.6 \%)$ and adverse outcome in 4 children (11.4\%). In the HIE grade III group a favourable outcome was described in 3 children (18.7\%), 13 children (81.3\%) had an adverse outcome. Table 2 shows the change in lactate over time, with a statistically significant difference between the two groups. From these results it can be judged that lactate could be an auxiliary predictor of the development of neonates with HIE grades II and III. Fig. 1 clearly shows that in both groups, lactate tends to decrease over time. Nevertheless, its absolute value in the blood is of key importance regarding favourable patient outcome.

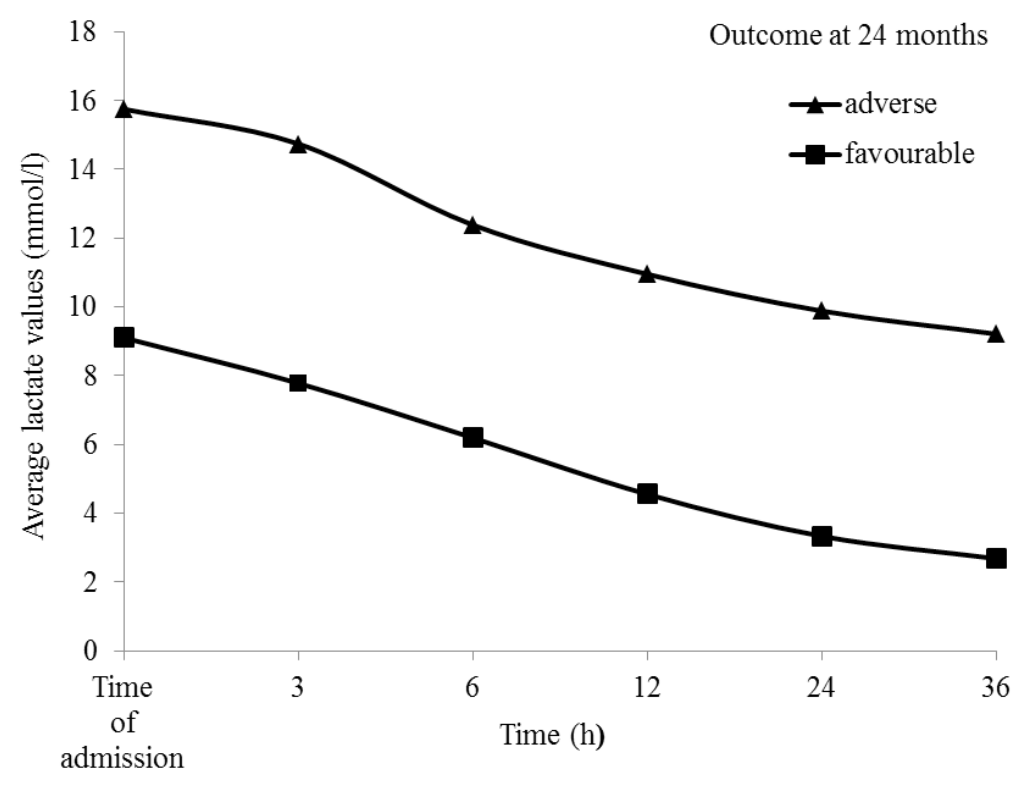

Fig. 1. Graphical representation of the change in lactate values in both groups of patients. 


\section{DISCUSSION}

In neonatal practice, lactate is not normally used to estimate HIE treatment outcome as its role as a prognostic marker has not yet been verified.

In the past, lactate was considered to be only a byproduct of anaerobic metabolism - "waste" accumulated in the body as a result of insufficient oxygenation of metabolically active tissue. Today it is known that, together with other ketone bodies, it can be a source of energy for the heart and brain. Recently it has also been attributed with a key role in providing information on the organism's metabolic state. A significant mediator, it can impact the metabolism of cells far from their site of origin by regulating the formation of cAMP via the GPR81 lactate receptor, and by influencing the ratio of NADH / NAD+. Both processes are associated with the regulation of energy in the brain and indirectly, blood flow ${ }^{16}$. Lactate also functions as a "critical buffer" which enables an increased rate of glycolysis to meet increased energy demands due to stress. Lactate dynamics and their prognostic significance have so far been intensively monitored in critically ill adult patients. In septic and traumatic adults, it has been shown that persistently high lactate levels during treatment are linked with higher mortality and morbidity ${ }^{17}$. Additionally, better results were seen in cases of adult post-resuscitation syndrome treated with $\mathrm{TH}$ where lactate values did not increase further, but rather fell ${ }^{18}$. Studies in veterinary medicine have identified persistently elevated lactate levels as a reliable independent biomarker predicting mortality in critically ill newborn foals ${ }^{19,20}$. On the other hand, some animal studies suggest a neuroprotective effect if lactate is administered intraventricularly into the brain of newborn rats immediately after ischaemia. These young were subsequently found to have significantly smaller lesions in basal ganglia. In cases where the application of lactate was delayed (after $1 \mathrm{~h}$ of reperfusion or later) the neuroprotective effect was no longer demonstrated ${ }^{21}$. In human medicine however, there is very little evidence for the relationship between lactate levels and the prognosis of children following trauma. Although an isolated reading of elevated lactate value may be misleading in a paediatric patient, lactate clearance, i.e. the time at which lactate returns to normal, may be important in determining the prognosis of injured children ${ }^{22}$. In the neonatal population, elevated postnatal lactate levels have been described only in terms of being a risk factor indicating the possible onset and development of severe postpartum asphyxia $^{23}$. A connection has been established between postpartum hyperlactataemia and a higher instance of neurological morbidity and mortality in neonates in the first days of life ${ }^{24-26}$. However, lactate dynamics as a potential predictor of the long-term outcome of asphyxiated newborns have yet to be comprehensively studied. A 2015 study comprising 12 asphyxiated newborns undergoing TH highlighted the fact that elevated serum lactate levels may be associated with adverse psychomotor development at 24 months $^{27}$.

The initial lactate value clearly correlates with the severity of the hypoxic injury. After the initial rise, it usually returns to normal. Slowdowns in the reduction of lactate in animal subjects were attributed to reduced liver clearance and increased production of lactate in the stimulation of glycolysis and sympathoadrenal system, and concomitant cramping activity respectively ${ }^{28}$. It should be noted that secondary elevations of lactate levels during the first 4 days of life may indicate suboptimal haemodynamic conditions in term-asphyxiated newborns treated with $\mathrm{TH}\left(\right.$ ref. $\left.^{29}\right)$. The incidence of hypotension in asphyxial newborns is approximately $51 \%\left(\right.$ ref. $^{30}$ ). This is due to reduced cardiac contractility and decreased cardiac output, most often due to myocardial dysfunction with the onset of asphyxia and hypothermia ${ }^{31}$. In our sample cohort, $88 \%$ of subjects were treated for hypotension in order to keep the mean BP above the gestational age limit, ideally with adequate diuresis.

One caveat is that lactate values can be influenced by a number of factors. Tissue hypoxia during HIE is a pivotal factor that can increase the amount of lactate in the body of the newborn. That said, a number of factors can definitively be ruled out in our sample cases: severe sepsis, intense short-term sports activity, diabetic coma, poisoning (carbon monoxide, alcohol, methanol and cyanide), methaemoglobinaemia, leukaemia, toxic hepatopathy, mitochondrial myopathy, pyruvate carboxylase deficiency metabolism and type I glycogenosis. However, the actual body temperature may also contribute to the production of lactate, along with the state of perfusion in the skin and splanchnic system. In asphyxiated neonates, $\mathrm{TH}$ is initiated not later than $6 \mathrm{~h}$ after birth (the therapeutic window) and ideally as soon as the indication criteria for the treatment have been established ${ }^{14}$. The values of lactate measured in our sample at the $3^{\text {rd }}$ and $6^{\text {th }} \mathrm{h}$ of life could have been greatly influenced by significant temperature variance.

One limitation that could be identified in this study was that the standardized Bayley Scales of Infant Development (BSID) test was not carried out at 2 years ${ }^{32}$. This would have conclusively established the sample cohort's level of mental and psychomotor development. At the time of the study, this method was not standard practice in our department. If BSID had been considered necessary to the evaluation of the study, the sample size would have been significantly reduced. The GMFCS scale, together with sensory perception assessment, was deemed sufficient for evaluating the clinical state of surviving patients. An additional limiting factor is the fact that a 2-year-old without apparent neurological or cognitive impairment could encounter cognitive and memory problems by school age; therefore, it would be better to monitor the subjects until at least 6 years old. The final criticism can be directed at the differing ages of the neonates included in the study (from 0-6 h), as those born outside needed to be transported to the perinatal centre.

\section{CONCLUSION}

Based on current knowledge, it is hard to say whether lactate is the cause or consequence of HIE. However, the 
level of lactate in the body undoubtedly affects the metabolism of key energy processes in the brain. This study shows that excess lactate in the early stages of HIE may be linked to adverse outcomes in asphyxiated neonates. Hyperlactataemia may arise either from excessive lactate production, impaired degradation, or a combination of both. The subject requires further investigation.

Acknowledgement: The author wishes to thank prof. Jindrich Mourek, MD, DrSc., Institute of Physiology, 1st Faculty of Medicine at Charles University Prague, for invaluable advice on the issue of metabolic processes in asphyxiated newborns. D. Salounova was supported by ESF Project CZ.1.07/2.3.00/20.0296.

Author contributions: RP: literature search; RP, LK: manuscript writing; RP, LK: study design; RP: data collection; DS: data analysis; DS, RP: data interpretation; DS: statistical analysis, tables, figure; RP, LK, DS: final approval. Conflict of interest statement: None declared.

\section{REFERENCES}

1. Gomella TL. Neonatology: Management, Procedures, On-Cal Problems, Diseases, and Drugs, Sixth Edition. New York: McGrawHill; 2009.

2. Shah PS. Hypothermia: a systematic review and meta-analysis of clinical trials. Semin Fetal Neonatal Med 2010;15(5):238-46.

3. Edwards AD, Brocklehurst P, Gunn AJ, Halliday H, Juszczak E, Levene M, Strohm B, Thoresen M, Whitelaw A, Azzopardi D. Neurological outcomes at 18 month of age after moderate hypothermia for perinatal hypoxic ischemic encephalopathy: syntheses and metaanalysis of trial data. BMJ 2010;340:c363.

4. Sarnat HB, Sarnat MS. Neonatal encephalopathy folowing fetal distress. A clinical and electroencephalografic study. Arch Neuro 1976;33(10):696-705.

5. Perlman M, Shah PS. Hypoxic-ischemic encephalopathy: Challenges in outcome and prediction. J Pediatr 2011;158(2):51-4.

6. Murray DM, Bala P, O'Connor C, Ryan CA, Connolly S, Boylan GB. The predictive value of early neurological examination in neonata hypoxic-ischaemic encephalopathy and neurodevelopmental outcome at 24 months. Dev Med Child Neurol 2010;52(2):e55-9.

7. De Vries LS, Jongmans MJ. Long-term outcome after neonatal hypoxic-ischaemic encephalopathy. Arch Dis Child Fetal Neonatal Ed 2010;95:F220-224.

8. Li J, Funato M, Tamai H, Wada H, Nishihara M, Iwamoto H, Okazaki Y, Shintaku H. Predictors of neurological outcome in cooled neonates. Pediatr Int 2013;55(2):169-76.

9. Toet MC, Hellstrom-Westas L, Groenendaal F, Eken P, deVries LS. Amplitude integrated EEG 3 and 6 hours after birth in full term neonates with hypoxic-ischaemic encephalopathy. Arch Dis Child Fetal Neonatal Ed 1999;81(1):F19-23.

10. Hallberg B, Grossmann K, Bartocci M, Blennow M. The prognostic value of early aEEG in asphyxiated infants undergoing systemic hypothermia treatment. Acta Paediatr 2010;99(4):531-6.

11. Hanrahan JD, Cox IJ, Azzopardi D, Cowan FM, Sargentoni J, Bell JD, Bryant DJ, Edwards AD. Relation between proton magnetic resonance spectroscopy within 18 hours of birth asphyxia and neurodevelopment at 1 year of age. Dev Med Child Neurol 1999;41(2):76-82.

12. Amess PN, Penrice J, Wylezinska M, Lorek A, Townsend J, Wyat JS, Amiel-Tison V, Cady EB, Stewart A. Early brain proton magnetic resonance spectroscopy and neonatal neurology related to neurodevelopmental outcome at 1 year in term infants after presumed hypoxic-ischaemic brain injury. Dev Med Child Neurol 1999;41(7):436-45.

13. Lemmers PM, Zwanenburg RJ, Benders MJ, de Vries LS, Groenendaal F, van Bel F, Toet MC. Cerebral oxygenation and brain activity af- ter perinatal asphyxia: does hypothermia change their prognostic value? Pediatr Res 2013;74(2):180-5.

14. Kolarova (Polackova) R, Halek J, Kantor L, Pokorna P., Vobruba V, Tkaczyk H, Wiedermannova H, Zoban P. Řizená hypotermie v léčbě hypoxicko - ischemické encelalopatie. Doporučený postup České neonatologické společnosti, 2011. Available from: http://www. neonatology.cz/upload/www.neonatology.cz/Legislativa/Postupy/ hypotermie.pdf.

15. Palisano R, Rosenbaum P, Walter S, Russell D, Wood E, Galuppi B. Development and reliability of a system to classify gross motor function in children with cerebral palsy. Dev Med Child Neurol 1997;39(4):214-23.

16. Bergersen LH, Giedde A. Is lactate a volume transmitter of metabolic states of the brain? Front Neuroenergetics 2012;4:5. doi: 10.3389/ fnene.2012.00005.

17. Bakker J, Nijsten MW, Jansen TC. Clinical use of lactate monitoring in critically ill patients. Annals of Intensive Care 2013;3:12. doi: 10.1186/2110-5820-3-12.

18. Akin S. Therapeutic hypothermia for postresuscitation syndrome and lactate levels. In: Proceeding Second World Congress on Biomarkers \& Clinical Research; 2011 12-14 September; Baltimore, USA. J Mol Biomark Diag 2011; 2:4

19. Castagnetti C, Pirrone A, Mariella J, Mari G. Venous blood lactate evalution in equine neonatalintensive care. Theriogenology 2010;73(3):343-57.

20. Borchers A, Wilkins PA, Marsh PM, Axon JE, Read J, Castagnetti C, Pantaleon L, Clark C, Qura'n L, Belgrave R, Schwarzwald C, Levy M, Bedenice D, Saulez MN, Boston RC. Sequental L-lactate concentration in hospitalised equine neonates: A prospective multicentre study. Equine Vet J Suppl 2013;(45):2-7.

21. Berthet C, Lei H, Thevenet J, Gruetter R, Magistretti PJ, Hirt L. Neuroprotective role of lactate after cerebral ischemia. J Cereb Blood Flow Metab 2009;29(11):1780-9.

22. Lawton $L$, Crouch $R$, Voegeli D. Is lactate an effective clinical marker of outcome for children with major trauma? - A literature review. Int Emerg Nurs 2016;28:39-45. doi: 10.1016/j.ienj.2016.04.002.

23. Varkilova L. Blood lactate measurement as a diagnostic and prognostic marker tool after birth asphyxia in newborn infants with gestational age $>$ or $=34$ gestational weeks. Akush Ginekol 2013;52(3):36-43.

24. Fernandez HG, Vieira AA, Barbosa AD. The correlation between plasma lactate concentrations and early neonatal mortality. Rev Bras Ter Intensiva 2012;24(2):184-7.

25. Shah S, Tracy M, Smyth J. Postnatal lactate as an early predictor of short-term outcome after intrapartum asphyxia. J Perinatol 2004;24(1):16-20.

26. Silva SD, Hennebert N, Denis R, Wayenberg JL. Clinical value of single postnatal lactate measurement after intrapartu asphyxia. Acta Paediatr 2000;89(3):320-3.

27. Chiang MC, Lien R, Chu SM, Yang PH, Lin JJ, Hsu JF, Fu RH, Lin KL. Serum lactate, brain magnetic resonance imaging and outcome of neonatal hypoxic ischemic encephalopathy after therapeutic hypothermia. Pediatr Neonatol 2016;57(1):35-40.

28. Murray DM, Boylan GB, Fitzgerald AP, Ryan CA, Murphy BP, Connolly S. Persistent lactit acidosis in neonatal hypoxic-ischaemic encephalopathy correlates with EEG grade and electrographic seizure burden. Arch Dis Child Fetal Neonatal Ed 2008;93(3):F183-86.

29. Balushi AA, Guibault MP, Wintermark P. Secondary increase of lactate levels in asphyxiated newborns during hypothermia treatment: Reflect of suboptimal hemodynamics (a case series and review of the literature). AJP Rep 2016;ž(1):e48-58.

30. Jacobs SE, Berg M, Hunt R, Tarnow-Mordi WO, Inder TE, Davis PG. Cooling for newborns with hypoxic ischaemic encephalopathy. Cochrane database Syst Rev 2013;1:CD003311.

31. Cavallaro G, Filippi L, Raffaeli G, Cristofori G, Schena F, Agazzani E, Amodeo I, Griggio A, Boccacci S, Fiorini P, Mosca F. Heart rate and arterial pressure changes during whole-body deep hypothermia. ISRN Pediatr 2013;2013:140213.

32. Massaro AN, Evangelou I, Brown J, Fatemi A, Vezina G, McCarter R, Glass P, Limperopoulos C. Neonatal neurobehavior after therapeutic hypothermia for hypoxic ischemic encephalopathy. Early Hum Dev 2015;91(10):593-9. 